\title{
Role of the Skp1 prolyl-hydroxylation/ glycosylation pathway in oxygen dependent submerged development of Dictyostelium
}

\author{
Yuechi Xu', Zhuo A Wang ${ }^{2}$, Rebekah S Green ${ }^{1}$ and Christopher M West ${ }^{{ }^{*}}$
}

\begin{abstract}
Background: Oxygen sensing is a near universal signaling modality that, in eukaryotes ranging from protists such as Dictyostelium and Toxoplasma to humans, involves a cytoplasmic prolyl 4-hydroxylase that utilizes oxygen and a-ketoglutarate as potentially rate-limiting substrates. A divergence between the animal and protist mechanisms is the enzymatic target: the animal transcriptional factor subunit hypoxia inducible factor-a whose hydroxylation results in its poly-ubiquitination and proteasomal degradation, and the protist E3 ${ }^{\text {SCF }}$ ubiquitin ligase subunit Skp1 whose hydroxylation might control the stability of other proteins. In Dictyostelium, genetic studies show that hydroxylation of Skp1 by PhyA, and subsequent glycosylation of the hydroxyproline, is required for normal oxygen sensing during multicellular development at an air/water interface. Because it has been difficult to detect an effect of hypoxia on Skp1 hydroxylation itself, the role of Skp1 modification was investigated in a submerged model of Dictyostelium development dependent on atmospheric hyperoxia.
\end{abstract}

Results: In static isotropic conditions beneath 70-100\% atmospheric oxygen, amoebae formed radially symmetrical cyst-like aggregates consisting of a core of spores and undifferentiated cells surrounded by a cortex of stalk cells. Analysis of mutants showed that cyst formation was inhibited by high Skp1 levels via a hydroxylation-dependent mechanism, and spore differentiation required core glycosylation of Skp1 by a mechanism that could be bypassed by excess Skp1. Failure of spores to differentiate at lower oxygen correlated qualitatively with reduced Skp1 hydroxylation.

Conclusion: We propose that, in the physiological range, oxygen or downstream metabolic effectors control the timing of developmental progression via activation of newly synthesized Skp1.

Keywords: Prolyl 4-hydroxylase, Glycosyltransferase, Oxygen sensing, Hypoxia, Hydroxyproline, Cellular slime mold

\section{Background}

Cells, whether free-living or residing within multicellular organisms, continuously monitor environmental $\mathrm{O}_{2}$ and integrate this information with other cues to regulate their metabolism, growth and development. Cytoplasmic prolyl 4-hydroxylases (P4Hs) are key $\mathrm{O}_{2}$ sensors in animals $[1,2]$, owing to their ability to distribute the atoms of molecular $\mathrm{O}_{2}$ between the target Pro and the metabolite $\alpha$-ketoglutarate. The transcriptional co-factor hypoxia inducible factor- $\alpha(H I F \alpha)$ is a main target

\footnotetext{
* Correspondence: Cwest2@ouhsc.edu

'Department of Biochemistry and Molecular Biology, Oklahoma Center for Medical Glycobiology, University of Oklahoma Health Sciences Center, 975 NE 10th St., BRC 413, OUHSC, Oklahoma City, OK 73104, USA

Full list of author information is available at the end of the article
}

(Figure 1A), and hydroxylated HIF $\alpha$ is subject to polyubiquitination by the VHL (von Hippel-Lindau protein/ cullin-2/elongin B/elongin C) type of E3 ubiquitin ligases leading to subsequent degradation in the 26Sproteasome [2]. Thus low $\mathrm{O}_{2}$ is thought to rapidly induce the expression of new genes appropriate to hypoxia. In contrast, a $\mathrm{P} 4 \mathrm{H}$ in the social amoeba Dictyostelium and the human parasite Toxoplasma gondii, known as PhyA (previously referred to as $\mathrm{P} 4 \mathrm{H} 1$ ), appears to solely hydroxylate Skp1 (Figure 1B), at Pro143 [3,4]. Hydroxylation does not affect Skp1 stability [5] but may regulate poly-ubiquitination activity of the SCF (Skp1/ cullin-1/F-box) class of E3 ubiquitin ligases, of which Skp1 is an adaptor subunit [6,7]. The 4(trans)-hydroxyproline (Hyp) can then be sequentially modified by 5

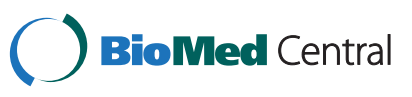




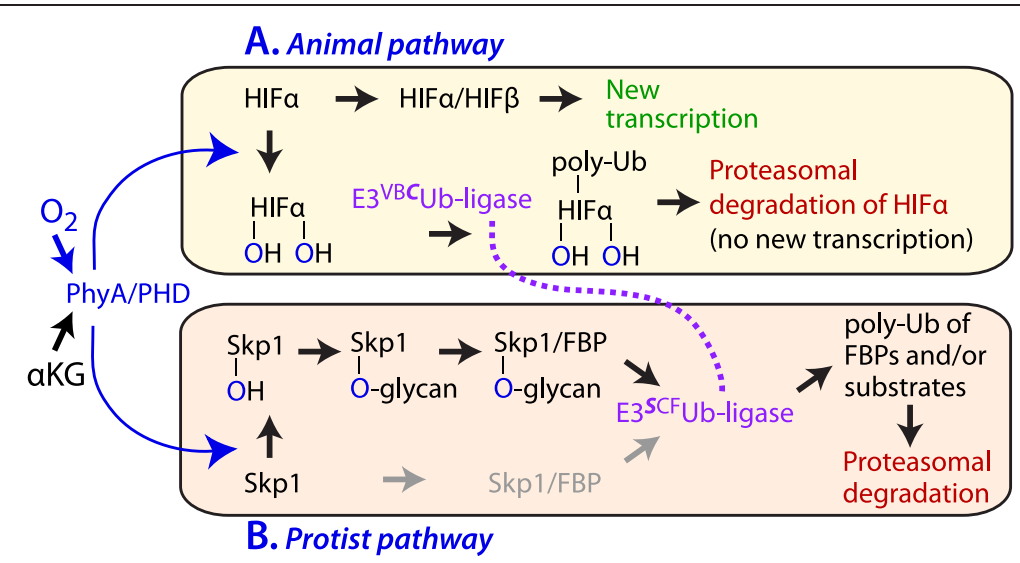

Figure 1 Schematic comparison of $\mathrm{O}_{2}$ and prolyl 4-hydroxylase signaling in animals and protists. (A) The upper panel shows current thinking about how $\mathrm{O}_{2}$ - and a-ketoglutarate (aKG)-dependent hydroxylation of 2 Pro residues of HIFa by PHD2 generates a degron recognized by $\mathrm{E}^{\mathrm{VBC}} \mathrm{Ub}$-ligase leading to its poly-ubiquitination and degradation in the 26S-proteasome, thereby interfering with its heterodimerization with HIF $\beta$ and induction of genes appropriate to response to low $\mathrm{O}_{2}[1,2]$. (B) The lower panel shows current thinking [11] about how the protist ortholog PhyA leads to hydroxylation and multi-step glycosylation of Pro143 (in Dictyostelium). Hydroxylation of Skp1 does not generate a degron [5], but it and glycosylation may affect interaction with F-box proteins (gray implies reduced activity; unpublished data) and consequently the poly-ubiquitination activity and proteasomal degradation of F-box proteins and/or substrates of the F-box proteins. Homology of elongin C of the

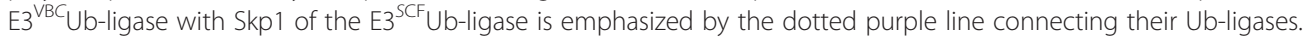

sugars whose additions are catalyzed by 5 glycosyltransferase activities encoded by 3 genes [5,8,9]. Reverse genetic analyses demonstrated that hydroxylation and glycosylation of Dictyostelium Skp1 are essential for normal $\mathrm{O}_{2}$ regulation of development [10,11], and recent studies showed its importance for optimal growth of Toxoplasma [4].

Dictyostelium development is ultrasensitive to $\mathrm{O}_{2}$ making it a good model for understanding the mechanism of $\mathrm{O}_{2}$ sensing by other organisms that conserve the Skp1 modification pathway. Development is induced by starvation, which signals the normally solitary phagocytic amoebae to form a multicellular fruiting body, which consists of a cellular stalk that aerially supports thousands of spores for potential dispersal to other locations (see Figure 2A in Results) [12-14]. Initially, the amoebae chemotax together to form a multicellular aggregate, which polarizes in response to environmental cues and elongates into a migratory slug consisting of prestalk cells mostly at its anterior end and prespore cells in the remainder. The slug responds to environmental signals that direct its migration and regulate the slug-to-fruit switch- the process of culmination leading to formation of the fruiting body. Signals include light, low $\mathrm{NH}_{3}$, low moisture, higher temperature, and high $\mathrm{O}_{2}$ which, in the native environment of the soil, draw the subterranean slug to above ground where culmination is most productive $[11,12,15-20]$. In the laboratory, the process takes place over the course of $24 \mathrm{~h}$ after deposition of amoebae on moist agar or filter surfaces wetted with low salt buffers. Whereas amoebae grow and form slugs at an air-water interface in the presence of as little as $2.5 \%$
$\mathrm{O}_{2}, \sim 10 \%$ is required for culmination [21], and slugs immersed in mineral oil require atmospheric hyperoxia to culminate [20]. Overexpression of Skp1 or absence of pathway activity drives the $\mathrm{O}_{2}$ requirement up to 18$21 \%$ (near ambient level), whereas decreased Skp1 or overexpression of PhyA drives the $\mathrm{O}_{2}$ requirement down to $5 \%$ or less $[5,10,11]$. These genetic manipulations also revealed effects on timing of slug formation and on sporulation. Together with studies on a Skp1 mutant lacking the modifiable Pro143 residue, and double mutants between Skp1 and pathway enzyme genes, the findings suggested that the Skp1 modification pathway mediates at least some $\mathrm{O}_{2}$ responses. However, $\mathrm{O}_{2}$ contingent modification of the steady state pool of Skp1 has not been demonstrated.

To address this issue, and to investigate the generality of $\mathrm{O}_{2}$ regulation of development, we turned to a previously described submerged development model in which terminal cell differentiation depends on high $(\geq 70 \%)$ atmospheric $\mathrm{O}_{2}[22,23]$. The wider range of $\mathrm{O}_{2}$ concentrations presented to cells in this setting may facilitate analysis of the dependence of Skp1 hydroxylation on $\mathrm{O}_{2}$, and absence of the morphogenetic movements of culmination might reveal later developmental steps that are dependent on Skp1 and its modifications. In a static adaptation of the previous shaking cultures, we observed that terminal cell differentiation occurs in a novel radially symmetrical fashion in multicellular cyst-like structures. Under these conditions, we find that $\mathrm{O}_{2}$ is apparently rate-limiting for Skp1 hydroxylation, and that cyst formation and terminal spore differentiation that require high $\mathrm{O}_{2}$ also depend on normal levels of Skp1 and 
both its hydroxylation and glycosylation. This expands the role of Skp1 and its modifications in developmental regulation, and supports the model that $\mathrm{O}_{2}$ regulates its modification in cells.

\section{Methods}

\section{Dictyostelium cell strains and growth}

The normal $D$. discoideum strain Ax3 and its derivatives with the following genotypes were described previously: phy $A^{-}$[3], ecmA::PhyA-myc/phy $A^{-}, \cot B::$ PhyA-myc/phy $A^{-}$[24], PKA(cat)/phy $A^{-}$[24], pgtA- [8], PgtA-N/pgtA ${ }^{-}$[8], agtA ${ }^{-}$[25], gmd ${ }^{-}$[26], ecmA:: Skp1A.1/Ax3, ecmA::Skp1A.2/Ax3, $\operatorname{cotB::Skp1A.1/Ax3,~}$ $\operatorname{cotB}:: S k p 1 A .3 / \mathrm{Ax} 3, \quad \operatorname{cotB}:: \mathrm{Skp} 1 \mathrm{~A} 3 . \mathrm{H} 2 / \mathrm{Ax} 3, \quad \operatorname{ecm} A::$ Skp1B.2/phy $A^{-}, \quad \operatorname{cotB}::$ Skp1A.2/phy $A^{-}, \quad \operatorname{cotB}::$ Skp1A.3/ $p h y A^{-}[10]$. Note that the number before the decimal point represents alleles, and the number after represents clones that may vary in expression level. Cells were grown in shaking $\mathrm{HL}-5$ axenic medium at $22^{\circ} \mathrm{C}$ [24], and collected before their density reached $0.8 \times 10^{7} / \mathrm{ml}$.

\section{Cell development}

Cells were harvested by centrifugation $(2000 \mathrm{~g} \times 1 \mathrm{~min})$ at $4^{\circ} \mathrm{C}$, resuspended in PDF buffer $\left(33 \mathrm{mM} \mathrm{NaH}_{2} \mathrm{PO}_{4}\right.$, $10.6 \mathrm{mM} \mathrm{Na}_{2} \mathrm{HPO}_{4}, 20 \mathrm{mM} \mathrm{KCl}, 6 \mathrm{mM} \mathrm{MgSO}$, $\mathrm{pH}$ 5.8), re-centrifuged and resuspended in PDF at $10^{8} / \mathrm{ml}$, and deposited on $0.45 \mu \mathrm{m}$ pore Millipore cellulose nitrate filters for standard development at an air-water interface [27]. For submerged development, washed cells were resuspended in PDF at $2 \times 10^{7} / \mathrm{ml}$ and $1.4 \mathrm{ml}$ was deposited into each well of a 6-well bacteriological or tissue culture plate $(3 \mathrm{~cm}$ diameter wells). Plates were incubated for up to $72 \mathrm{~h}$ in a sealed plastic box, with inlet and outlet ports for gas flow, under room fluorescent lights at $22^{\circ} \mathrm{C}$. The inlet valve was connected via a bubbling water humidifier to a compressed gas tank formulated with the indicated percentage of $\mathrm{O}_{2}$, with the balance made up of $\mathrm{N}_{2}$. Previously it was shown that inclusion of $1 \% \mathrm{CO}_{2}$ did not affect the $\mathrm{O}_{2}$ dependence of culmination [24]. The outlet tube was connected to a Pasteur pipette held under water to monitor gas flow. Cultures were kept unstirred to prevent contact of cells or cell aggregates with the buffer surface, which led to polarization and/or floating fruiting bodies (data not shown). Volume and cell density were optimized for maximal spore differentiation at $100 \% \mathrm{O}_{2}$ (data not shown). Alternate buffers, including KP (17 mM potassium phosphate, $\mathrm{pH}$ 6.5), or Agg buffer (0.01 $\mathrm{M} \mathrm{NaPO}_{4}$, $\mathrm{pH}$ 6.0, $0.01 \mathrm{M} \mathrm{KCl}, 0.005 \mathrm{M} \mathrm{MgCl}_{2}$ ), yielded lower spore numbers.

Cell aggregates were visualized in a stereomicroscope using transmitted light, or using phase contrast illumination on an inverted microscope. For detection of cellulosic cell walls, samples were analyzed under epifluorescence illumination in the presence of $0.1 \%(\mathrm{v} / \mathrm{v})$ Calcofluor White ST (American Cyanamid) in $10 \mathrm{mM}$ potassium phosphate ( $\mathrm{pH} 8.0)$, using DAPI-filters. Multiphoton confocal microscopy was performed at the OUHSC Imaging Laboratory on a Leica SP2 MP Confocal microscope.

For determining spore numbers, samples were supplemented with $0.2 \% \mathrm{NP}-40$, and spores were counted in a hemacytometer. Spores were identified based on their resistance to detergent, shape, refractility, and labeling with Calcofluor White ST or anti-spore coat Abs. Spore plating efficiency was determined by spreading an aliquot of detergent-treated spores on SM agar in association with Klebsiella aerogenes, and dividing the number of colonies by the counted number of input spores.

\section{Immunofluorescence}

Spores were released from cysts by probe sonication in $0.2 \% \mathrm{NP}-40$ in KP, centrifuged at $13,000 \mathrm{~g} \times 10 \mathrm{~s}$, and resuspended in KP buffer. Spores were recovered from fruiting bodies on non-nutrient agar by slapping the inverted Petri plate on a counter and washing the spores from the lid, and processed in parallel. An aliquot was treated with $6 \mathrm{M}$ urea, $1 \%(\mathrm{v} / \mathrm{v})$ 2-mercaptoethanol in TBS (10 mM Tris-HCl, pH 7.4, $150 \mathrm{mM} \mathrm{NaCl}$ ) for 3 min at $100^{\circ} \mathrm{C}$ prior to dilution in cold TBS and recovery by centrifugation. Spore suspensions $\left(2 \times 10^{6} / 50 \mu \mathrm{l}\right)$ were deposited on glass slides onto which had been dried a $50-\mu \mathrm{l}$ volume of $10 \mu \mathrm{g} / \mathrm{ml}$ poly-L-lysine in $\mathrm{H}_{2} \mathrm{O}$. After $15 \mathrm{~min}$, non-bound spores were removed by aspiration and washing with TBS. The monolayer was incubated in $4 \mathrm{mg} / \mathrm{ml}$ hemoglobin in TBS for $5 \mathrm{~min}, 1 \mu \mathrm{g} / \mathrm{ml}$ $\mathrm{mAb} 83.5[28]$ in $4 \mathrm{mg} / \mathrm{ml}$ hemoglobin in TBS for $1 \mathrm{~h}$, TBS (5 washes), $2 \mu \mathrm{g} / \mathrm{ml}$ Alexa 568-conjugated Rabbit anti-mouse IgG (Molecular Probes/Invitrogen) in 3\% $(\mathrm{w} / \mathrm{v})$ bovine serum albumin in TBS, TBS (5 washes), and Vectashield mounting medium. Samples were analyzed through a $40 \times$ (N.A. 0.75) lens via the TRITCchannel of an Olympus epifluorescence microscope, and images were identically recorded using a SPOT Flex camera (Diagnostic Instruments) and processed using Photoshop CS3.

\section{Western blotting}

Developing cells were collected by centrifugation at $2000 \mathrm{~g} \times 1.5 \mathrm{~min}$ at $4^{\circ} \mathrm{C}$ and boiled for $2 \mathrm{~min}$ in Laemmli sample buffer containing $50 \mathrm{mM}$ DTT. Low $\mathrm{O}_{2}$ samples were first supplemented with $2 \mathrm{mM}$ sodium dithionite [5] to minimize possible hydroxylation during sample preparation. Whole cell lysates were resolved by SDS-PAGE on a 4-12\% gradient gel (NuPAGE Novex, Invitrogen), and transferred to nitrocellulose membrane using an iBlot system (Invitrogen). Blots were probed with primary and fluorescent secondary Abs as described [10]. Blots were 
blocked in, and Abs were dissolved in, 5\% non-fat dry milk in $20 \mathrm{mM}$ Tris- $\mathrm{HCl}$ ( $\mathrm{pH} 7.4), 150 \mathrm{mM} \mathrm{NaCl}, 0.02 \%$ $\mathrm{NaN}_{3}$, and Alexa 680 fluorescence was imaged using a LiCor Odyssey scanner. Prespore cell differentiation was probed using mAbs 5F5 and 83.5 [28], and Skp1 isoforms were detected using pAb UOK87 [5], pAb UOK85 [5], mAb 4H2 [29], mAb 1C9 [29], and mAb 4E1 [3]. Affinitypurified anti-actin was from Sigma Chemical Co.

Images were analyzed densitometrically using $\mathrm{NIH}$ Image $\mathrm{J}$. mAb 4E1 was used in its linear response range [10] to obtain the fraction of Skp1 that was not modified. Initially, values for each upper and lower band were corrected for general background by subtraction of a blank intensity value obtained from the vicinity of the band of interest. Studies using pAb UOK87, which selectively recognizes unmodified Skp1, showed that $5 \%$ of Skp1 was unmodified at $100 \% \mathrm{O}_{2}$ based on comparison with a $p h y A^{-}$sample (not shown). The remaining density in the lower band of the $100 \% \mathrm{O}_{2}$ sample is of uncertain identity but, since its level was observed to be proportionate to the level of the upper band (not shown), its value (as a fraction of the upper band) was subtracted from each sample in the $\mathrm{O}_{2}$ series. The fraction of unmodified Skp1 was determined by dividing the corrected intensity of the lower Skp1 band by the sum of the intensities of the lower and upper bands.

\section{Results}

\section{Terminal differentiation at an air-water interface}

D. discoideum amoebae develop to form fruiting bodies when dispersed in a low ionic strength buffer on a moist surface (Figure 2A). About $75 \%$ of the cells become aerial spores and the remainder form the structural stalk. At reduced $\mathrm{O}_{2}$ levels (2.5-10\%), the slug intermediate continues to migrate on the surface without culminating $[24]$. When returned to the ambient $\mathrm{O}_{2}$ level (21\%), culmination then occurs within about $5 \mathrm{~h}$. To determine the minimal time required for exposure to ambient $\mathrm{O}_{2}$, slugs were exposed to $21 \% \mathrm{O}_{2}$ for varying times before returning to low $\mathrm{O}_{2}$. Figure $2 \mathrm{~B}$ shows that exposure to high $\mathrm{O}_{2}$ can be as brief as $1 \mathrm{~h}$, though up to $4 \mathrm{~h}$ is required for maximal culmination based on spore counts. The requirement for high $\mathrm{O}_{2}$ appeared to be selective for induction of culmination, because terminal cell differentiation occurred normally even within the fruiting bodies formed after only $1 \mathrm{~h}$ of exposure to normoxia (data not shown). The effect of $\mathrm{O}_{2}$ appears to be mediated at least in part by prolyl 4-hydroxylation of Skp1, because elevated $\mathrm{O}_{2}$ levels are required by $p h y A^{-}$ and Skp1-overexpression strains, and lower $\mathrm{O}_{2}$ is required by PhyA overexpression and $\mathrm{Skp}_{1} \mathrm{~B}^{-}$cells $[10,24]$. To further explore the role of Skp1 modification in $\mathrm{O}_{2}$ sensing and the importance of culmination as the target of regulation, we turned to a previously described
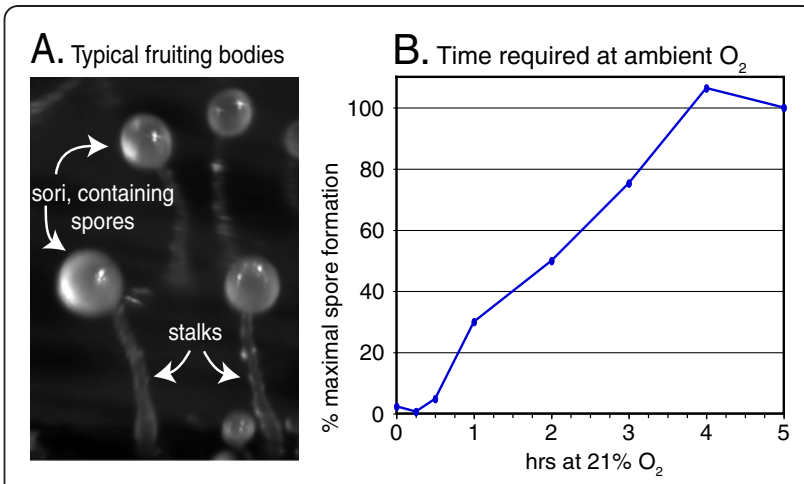

Figure $2 \mathrm{O}_{2}$ exposure required for culmination on filters. (A) Morphology of typical strain Ax3 fruiting bodies formed at $24 \mathrm{~h}$ at an air-water interface on filters in ambient atmosphere $\left(21 \% \mathrm{O}_{2}\right)$. Spores exclusively comprise the sori, which are supported aerially by cellular stalks. (B) Cells were allowed to develop for $12 \mathrm{~h}$ to the tipped aggregate stage before elongating to slugs, in an atmosphere of $5 \% \mathrm{O}_{2}$. Filters were transferred to ambient atmosphere $\left(21 \% \mathrm{O}_{2}\right)$ for the indicated period of time before return to $5 \% \mathrm{O}_{2}$ to complete development. Culmination was quantitated by counting spores, which correlated with fruiting body formation (not shown). Results are typical of 2 independent trials.

submerged development model $[22,23,30]$, in which progress beyond the loose aggregate stage is strictly dependent on elevated atmospheric $\mathrm{O}_{2}$, and terminal differentiation bypasses the morphogenetic movements of culmination.

\section{Terminal differentiation in submerged cultures}

When normal strain Ax3 cells were incubated at a similar density under a height of several $\mathrm{mm}$ of PDF buffer under room light illumination, rather than on a surface wetted with the same buffer, development proceeded only to the loose aggregate stage. However, when the atmosphere above the culture was maintained at 70 or $100 \% \mathrm{O}_{2}$, the majority of cells formed tight spherical aggregates with diameters of 100-250 $\mu \mathrm{m}$ (Figure 3A) and optically dense cores (see Figure 4D below). These cell aggregates were uniformly bounded by Calcofluorpositive stalk cells, distinguished by their polygonal shapes due to cell expansion during terminal differentiation (Figure 3A). Confocal microscopy revealed that the stalk cells comprised a cortex surrounding an interior region of spore-like cells, based on their characteristic ellipsoid profiles, with an uneven boundary at the interface (Figure 3B). Note that Figures 3 and 4 also include comparative data on $p h y A^{-}$cells (which do not modify Skp1), which will be described below. The interior cells could be liberated under pressure and consisted of a mixture of spores and undifferentiated (Calcofluor-negative) cells (Figure 3D). In contrast, the stalk cells remained associated with the deflated cyst-like structures. Maximal spore number was achieved by $2 \mathrm{~d}$ 


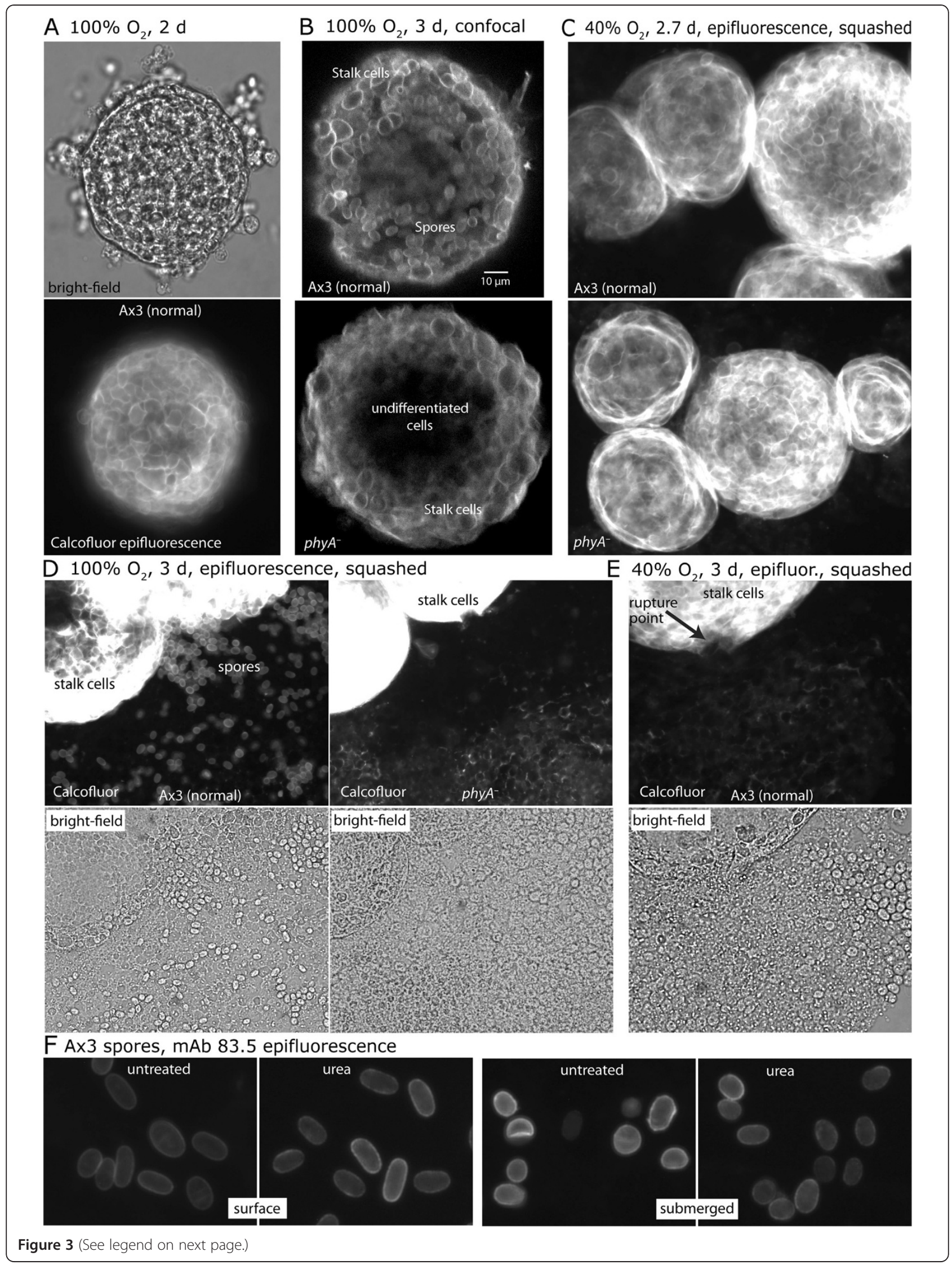


(See figure on previous page.)

Figure 3 Cell differentiation in submerged conditions. Typical cyst-like structures formed by unstirred suspensions of strain Ax3 (normal) or phy $A^{-}$cells under the atmosphere of $\mathrm{O}_{2}$ percentage and for the duration indicated. (A) An Ax3 aggregate formed in $100 \% \mathrm{O}_{2}$ was imaged by phase contrast (above), or epifluorescence microscopy in the presence of Calcofluor White ST (below) to reveal cell walls of terminally differentiated stalk cells at the aggregate surface. (B) Visualization of the interior of Ax3 and phy $A^{-}$aggregates using multiphoton confocal fluorescence microscopy in the presence of Calcofluor. (C) Aggregates of $A \times 3$ or phy $A^{-}$cells formed under $40 \% \mathrm{O}_{2}$ were squashed by applying vertical pressure to the cover slip, expelling some of the cellular contents resulting in wrinkling of the aggregate surface (evident as concentric folds appearing as rings). Cells were imaged for Calcofluor fluorescence. (D, E) Aggregates formed under $100 \% \mathrm{O}_{2}$ (D) or $40 \% \mathrm{O}_{2}$ (E) were similarly imaged, but exposure was adjusted to show fluorescence of expelled cells (absent in panel $\mathbf{C}$ ), resulting in overexposure of the stalk cellrich case. The point of emergence (rupture) of interior cells is indicated in panel E. (F) Spore coat formation. Spores from normal fruiting bodies developed at an air-water interface, and from submerged cultures maintained for $3 \mathrm{~d}$ under $70 \% \mathrm{O}_{2}$, were compared by immunofluorescence labeling with mAb 83.5, which recognizes the fucose epitope predominantly on the spore coat proteins SP96 and SP75. Spores were labeled before or after extraction with urea/2-mercaptoethanol to permeabilize the coat. Control samples lacking mAb 83.5 exhibited only dim internal fluorescence (not shown).

(Figure 4A), and ranged from 6 to 33\% of the input cell number. These spores tended to be less elongated than their counterparts formed in fruiting body sori (see Figure 3F below), suggesting imperfect synchronization of spore coat assembly processes [28]. To test their authenticity, spores were released by probe sonication in a non-ionic detergent, which ruptured the cyst-like structures and lysed non-spore cells. Spores from cysts were on average slightly more brightly labeled than authentic spores isolated from fruiting bodies by immunofluorescence probing with $\mathrm{mAb} 83.5$, which binds to the fucose epitope associated with the spore coat proteins SP96 and SP75 (Figure 3F). Surface labeling was retained even after boiling the spores in urea, indicating tight association of residual coat proteins with spore coat. To test spore function, equal numbers of spores prepared in this way were serially diluted in a clonal assay in association with $K$. aerogenes bacteria. The plating efficiency of cyst spores was $70 \%$, similar to that of spores collected from fruiting bodies on filters, which was $66 \%$. Thus, terminal cell differentiation occurred in radially symmetrical fashion in the absence of the normal morphogenetic movements of culmination. This contrasts with the slug-like elongated and linearly polarized aggregates formed when cells were agitated in high $\mathrm{O}_{2}[22,23]$. The radially polarized organization may result from a more uniform environment presented by the static setting in which polarizing gradients of $\mathrm{O}_{2}$ or $\mathrm{NH}_{3}$ fail to form.

Under $21 \% \mathrm{O}_{2}$, stalk cells and spores were rarely observed in the less compacted aggregates that form under these conditions. When present they occurred as clusters or single cells (not shown). At $40 \% \mathrm{O}_{2}$, larger aggregates were formed but they lacked dense cores observed at higher $\mathrm{O}_{2}$ levels. These cyst-like aggregates possessed a stalk cell cortex but their interior cells produced few spores, as visualized after squashing (Figures 3C,E). Though spores were not detected in this example, variable numbers were observed over the 5 independent trials as quantitated in Figure $4 \mathrm{C}$. The variation suggests that $40 \% \mathrm{O}_{2}$ is close to the threshold required for sporulation whose exact value is likely influenced by other factors, as observed for culmination [24]. To address the differentiation status of cells at the lower $\mathrm{O}_{2}$ levels, extracts were Western blotted for the spore coat precursor proteins SP85, SP96 and SP75 that are markers of prespore cell differentiation [31]. Whereas all 3 glycoproteins appeared in Ax3 cells by $24 \mathrm{~h}$ at $70 \% \mathrm{O}_{2}$, negligible expression occurred at $20 \%$ after 3 d (Figure 4E). Thus increasing $\mathrm{O}_{2}$ levels were required for tight aggregate formation, terminal stalk cell differentiation, and differentiation of the interior prespore cells into spores. It is likely that metabolic $\mathrm{O}_{2}$ consumption results in intracyst hypoxia in these unstirred cultures which, in the submerged state, is not adequately replenished by $\mathrm{O}_{2}$ diffusion. The finding that elevated $\mathrm{O}_{2}$ tension in the atmosphere above the medium can rescue terminal differentiation indicates that $\mathrm{O}_{2}$ availability is the limiting factor for terminal cell differentiation in this setting. It is not evident whether the higher $\mathrm{O}_{2}$ level required for spore compared to stalk cell differentiation reflects a higher $\mathrm{O}_{2}$ threshold requirement for spore differentiation or lower $\mathrm{O}_{2}$ in the aggregate centers.

\section{Requirement of PhyA for sporulation in submerged conditions}

A previously described mutant strain disrupted at its phyA locus [24] was analyzed to determine the involvement of Skp1 prolyl 4-hydroxylation in submerged development. phy $A^{-}$cells formed cyst-like structures at 40 $100 \% \mathrm{O}_{2}$ with outer layers of differentiated stalk cells, similar to the normal Ax3 strain (Figure 3C, D). However, interior cells failed to differentiate as spores, even after extended periods, as shown in the side-by-side comparisons in Figures 3B, D, 4A, and D. Instead, they remained as prespore cells, based on Western blot analysis showing abundant expression of the spore coat precursors (Figure 4E). Failure to sporulate was due to the PhyA deficiency, because $p h y A^{-}$cells complemented with ecmA::phyA or $\cot B:: p h y A$, which overexpress PhyA activity in prestalk or prespore cells respectively [24], 
A. $\mathrm{O}_{2}-$ \& PhyA-dependence

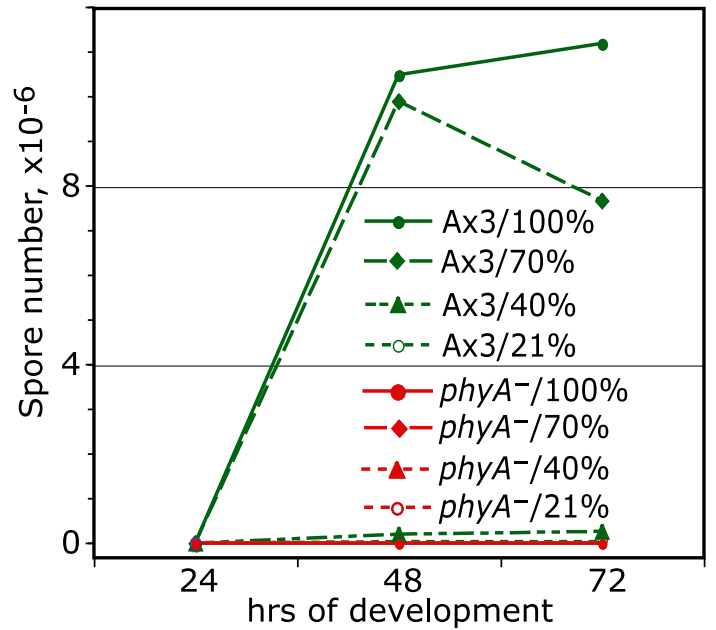

C. PhyA overexpression

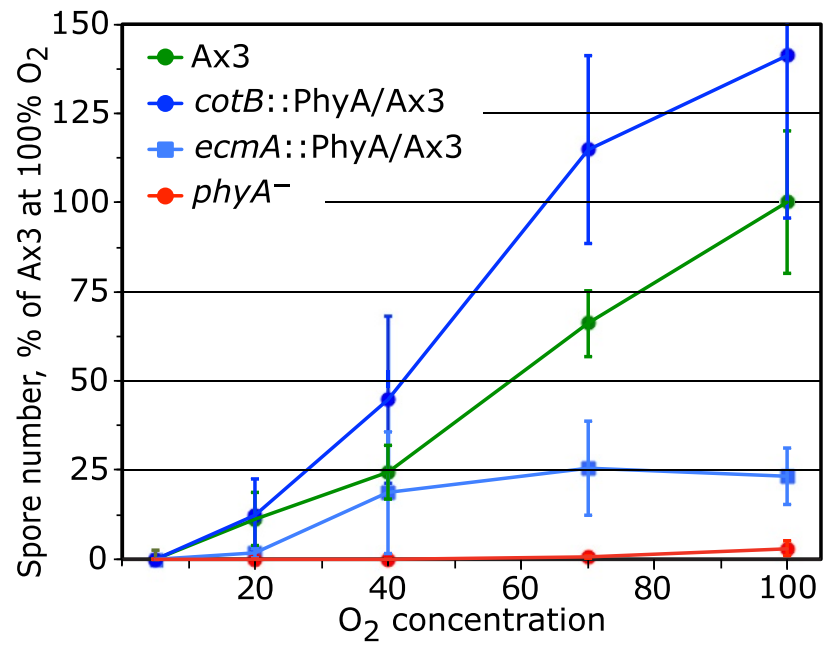

E. Prespore cell differentiation
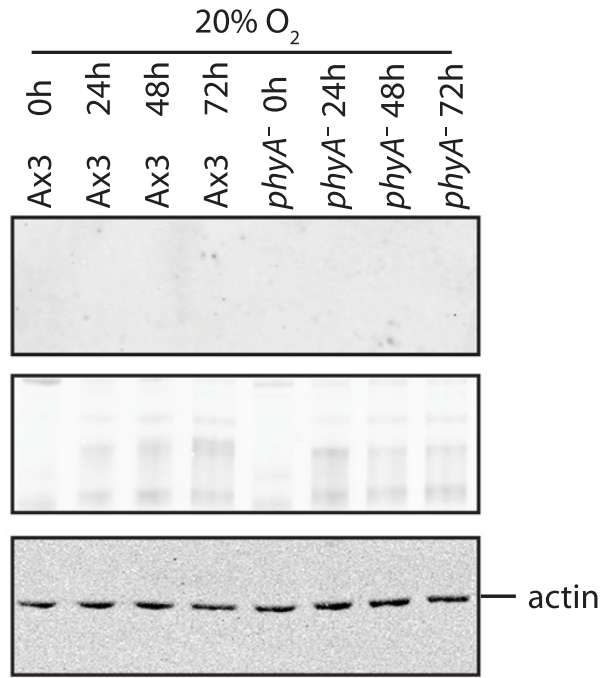

B. Rescue of phyA-disruption at $100 \% \mathrm{O}_{2}$

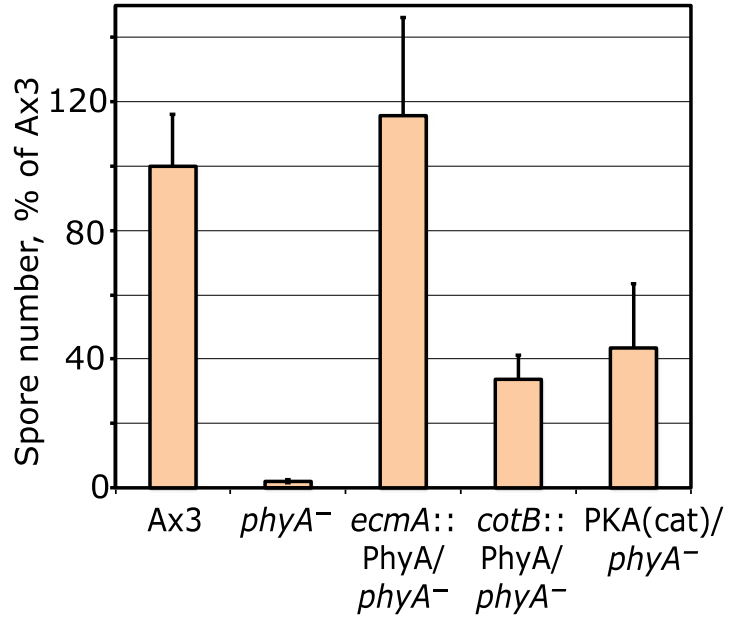

D. Aggregate morphologies
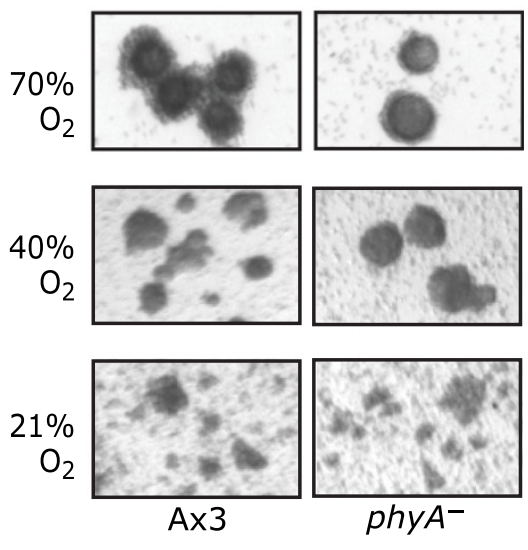

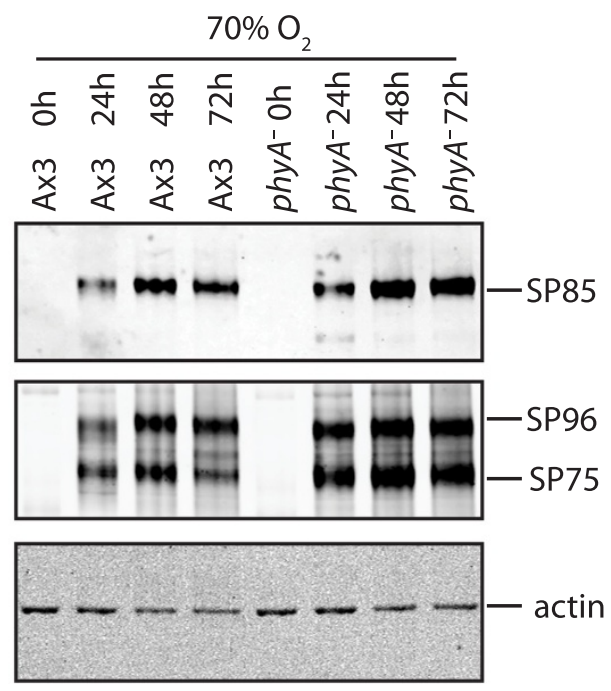




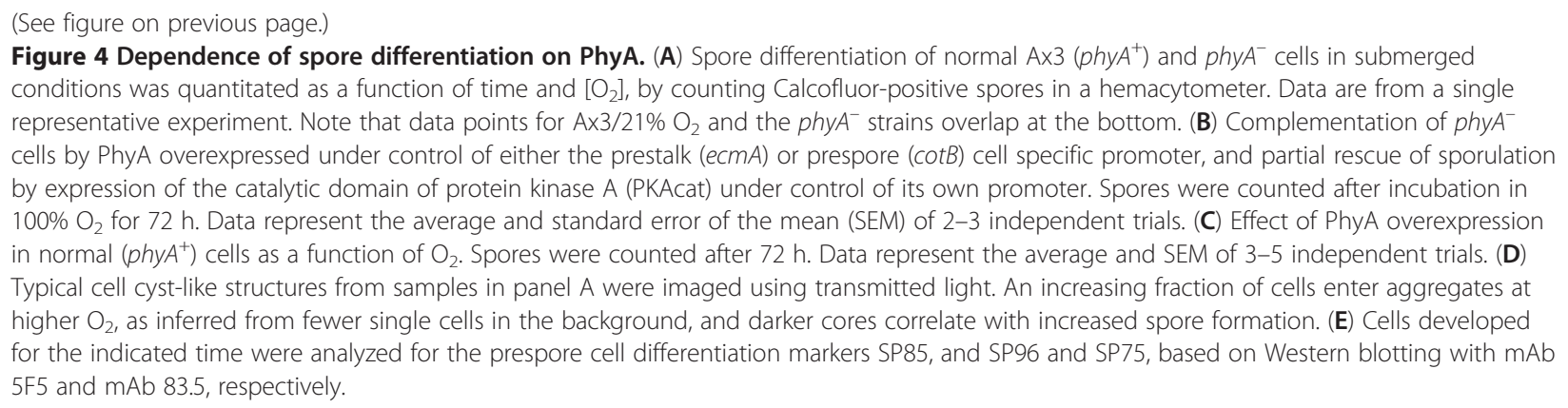

were rescued at high $\mathrm{O}_{2}$ (Figure $\left.4 \mathrm{~B}\right)$. ecmA::phyA/phy $A^{-}$ cells formed normal numbers of spores compared to Ax3, while $\cot B:: p h y A / p h y A^{-}$only partially rescued spore formation to about $30 \%$ of Ax3 levels. The difference suggests that prestalk cells may be important in mediating the role of PhyA in sporulation, consistent with evidence for a role of prestalk cells in processing or mediating sporulation signals during normal culmination [32-34]. While overexpression in prespore cells ( $\cot B$ promoter) was also partially effective, the possibility that PhyA signals autonomously in prespore cells is not proved because on filters, $\cot B:: \mathrm{PhyA}^{\text {oe }}$ cells tend to migrate to the tip in chimeras with normal cells [24]. Successful complementation from these developmental promoters confirmed that cells had differentiated into prestalk and prespore cells in the absence of PhyA, and showed that PhyA is required only after their appearance. Since spore formation selectively depended on high $\mathrm{O}_{2}$ and the threshold for spore (but not stalk cell) differentiation was specifically affected by the absence of PhyA, PhyA activity appears to have a novel function in mediating $\mathrm{O}_{2}$ regulation of spore differentiation.

Since overexpression of PhyA in a $p h y A^{+}$(wild-type) background reduces the $\mathrm{O}_{2}$ level required for culmination on filters [24], the effect of PhyA overexpression on sporulation was investigated. As shown in Figure 4C, modestly increased sporulation was observed at $70 \% \mathrm{O}_{2}$ when PhyA was overexpressed in prespore cells. However, overexpression in prestalk cells inhibited sporulation, without affecting cyst formation per se. As noted above, PhyA overexpression under the $e c m A$ promoter in a $p h y A^{-}$background rescued sporulation better than under the $\cot B$ promoter, so the inhibitory effect of overexpression in $p h y A^{+}$cells appears to be depend on a complex interplay between relative levels of expression in the different cell types rather than a cell autonomous effect on prestalk cells.

\section{Skp1 modification is $\mathrm{O}_{2}$ dependent}

To determine if Skp1 hydroxylation is affected by $\mathrm{O}_{2}$ availability, its modification status was assessed by Western blotting with pan- and isoform-specific Abs. Extensive analysis of soluble Skp1 from growing and developing cells shows that $\geq 90 \%$ of the steady state pool is homogenously modified by the pentasaccharide, and $\sim 5 \%$ exists in unmodified form. Fully modified and unmodified Skp1 migrate as a doublet in SDS-PAGE and, though the resolution of the doublet is compromised when whole cell extracts are analyzed, isoform-specific Abs indicate that total cell Skp1 is modified to a similar extent $[5,10]$. After $1 \mathrm{~d}$ of submerged development, total Skp1 from 40,70 or $100 \% \mathrm{O}_{2}$ cells migrated mainly as the upper band using $\mathrm{mAb} 4 \mathrm{E} 1$ that recognizes all Skp1 isoforms (Figure 5B). In comparison, 5\% $\mathrm{O}_{2}$ cells accumulated substantial Skp1 in the position of the lower band. This band corresponds to unmodified Skp1 based on reactivity with pAb UOK87 (Figure 5A). UOK87 preferentially binds unmodified Skp1 but exhibits weak reactivity with all Skp1 isoforms, so the upper band is also labeled. The lower band was not recognized by pAb UOK85 or mAb 1C9, which are specific for HO-Skp1 and GlcNAc-O-Skp1, respectively (data not shown). Quantitation of 5 independent samples indicated that the fraction of unmodified Skp1 decreased from $41 \%$ at $5 \% \mathrm{O}_{2}$, to $24 \%$ at $21 \% \mathrm{O}_{2}$ and $5 \%$ at $40 \%$ and higher levels (Figure 5D). Similar results were observed after 2 $\mathrm{d}$ of development except that the fraction of unmodified Skp1 at the lower $\mathrm{O}_{2}$ levels was slightly increased (data not shown). Since Skp1 turns over slowly with a half-life of $12-18 \mathrm{~h}$ during filter development $[5,35]$, it is likely that the appearance of non-glycosylated Skp1 was the result of new synthesis and that at 5 and $21 \%, \mathrm{O}_{2}$ is rate limiting for Skp1 hydroxylation. As shown in panel E, sporulation depended on higher levels of $\mathrm{O}_{2}$ than required to hydroxylate $\mathrm{Skp} 1$. Although $40 \% \mathrm{O}_{2}$ was sufficient to ensure that the steady-state pool of Skp1 was maximally hydroxylated within the sensitivity of our assay, a delay in hydroxylation of nascent Skp1 of several hrs would have escaped our detection, and may be biologically relevant for sporulation (see Discussion).

\section{Role of glycosylation in submerged development}

Disruption of phyA also blocks hydroxylation-dependent glycosylation of Skp1, which occurs according to the scheme in Figure 6A. To investigate the role of 
glycosylation per se, gnt1.3, pgt $A^{-}, g m d^{-}, p g t A-N / p g t A^{-}$, and $a g t A^{-}$cells, which accumulate Skp1 with zero, one, two, two, or three sugars respectively $[5,8,26]$ on account of enzyme gene disruptions, were analyzed. The strains expressing up to two sugars formed cyst-like structures which, however, failed to acquire dense-cores or induce spore formation, like phy $A^{-}$cells (Figure 6B, C). In contrast, agt $A^{-}$cells, which accumulate the trisaccharide form of Skp1 [25], were inconsistent in spore formation with numbers ranging from essentially zero to more than Ax3. Thus although the final two sugars were not always required for sporulation, their absence appears to make sporulation vulnerable to an unknown variable. Potential sources of variation include $\mathrm{NH}_{3}$ and light, which were previously shown to influence the $\mathrm{O}_{2}$ threshold for culmination on filters [24], and conditioned medium factors previously detected during submerged development [30]. Taken together, the results suggest that the role of hydroxylation may be simply to support glycosylation. This contrasts with culmination, in which hydroxylation alone partially rescues the normal $\mathrm{O}_{2}$ requirement of $p h y A^{-}$cells [5], an effect that is reversed by the action of PgtA in the absence of AgtA [9].

\section{Role of Skp1 and its modifications in submerged development}

The role of Skp1 itself was investigated by overexpression in different genetic backgrounds. Native Skp1 sequences were employed because a previous study showed that $\mathrm{N}$ - or $\mathrm{C}$-terminal peptide tags interfere with its hydroxylation and activity in cells [10]. Overexpression of Skp1B under the ecmA (prestalk) promoter inhibited tight aggregate formation even at $100 \% \mathrm{O}_{2}$ (Figure 7A-2). No spores (Figure 7B) and few stalk cells (not shown) were observed, confirming inability to progress past this early stage. Similar results were observed with a strain overexpressing the closely related isoform Skp1A (which differs by a single amino acid), or when either Skp1 was expressed under control of the $\operatorname{cotB}$ promoter (Figure 7B). However, overexpressing mutant Skp1A3(P143A), which cannot be modified, did not interfere with aggregation (Figure 7), and wild-type Skp1 overexpression failed to inhibit cyst formation in the absence of PhyA (Figure 7A-4). These strains did not form cyst-like structures or spores at lower $\mathrm{O}_{2}$ levels (data not shown), implying that high $\mathrm{O}_{2}$ also provides an additional, possibly metabolic, function important for development. The opposing effects of Skp1 overexpression and blocking its modification suggests that modification stimulates Skp1 activity, which can be modeled as breakdown (by a specific E3 ${ }^{\mathrm{SCF}}$ ubiqutin ligase) of a hypothetical activator of cyst formation.

In comparison, the requirement of Skp1 glycosylation for sporulation suggests that for this later developmental

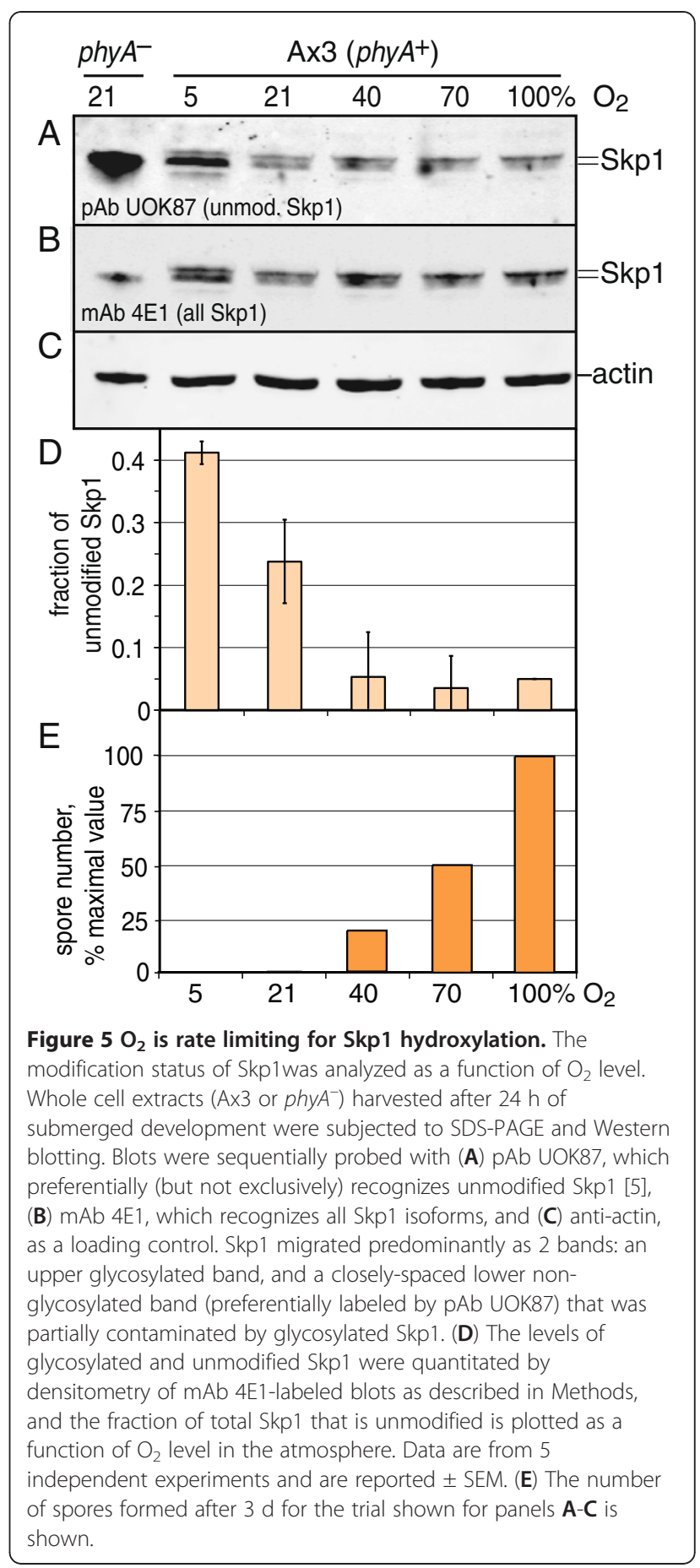

step, Skp1 contributes to the breakdown of a hypothetical inhibitor of sporulation. Without modification, Skp1 is not activated and the inhibitor accumulates. However, overexpression of Skp1 in the $p h y A^{-}$background (thereby bypassing the block to cyst formation) allows sporulation, which can be interpreted as providing additional activity to compensate for lack of activation by modification (Figure 7B, blue bars and inset; data not 
shown). Similar effects were observed irrespective of the promoter used, or whether wild-type Skp1A or B, or mutant Skp1, was overexpressed (data not shown). However, overexpression of Skp1 at very high levels did not rescue sporulation in $p h y A^{-}$cells as well, which might reflect a dominant negative effect toward SCF-complex formation. Separate effects on activators and inhibitors may depend on involvement of distinct F-box proteins.

\section{Discussion}

Three novel observations regarding development under submerged conditions are presented here: i) In the presence of high $\mathrm{O}_{2}$ and absence of stirring, cell differentiation occurs in a radially symmetrical rather than the typical linearly polarized pattern. With their outer husklike cortex and interior germinative cells, these structures have the organization of multicellular cysts as occur in animal tissues. The cyst-like structures are distinct from other terminal states formed by Dictyostelium, including the dormant unicellular microcyst and the multinucleated macrocyst [36]. Although conditions leading to the formation of cyst-like structures are not known to occur naturally, its $\mathrm{O}_{2}$ dependence is likely to be relevant to interpreting $\mathrm{O}_{2}$ signaling in normoxia as outlined below. ii) Skp1 hydroxylation is limited by $\mathrm{O}_{2}$ availability. iii) Certain developmental transitions that occur during submerged development, including tight aggregate formation and terminal spore differentiation, critically rely on hydroxylation and glycosylation of Skp1. Together, these findings reinforce a role for environmental $\mathrm{O}_{2}$ for influencing polarity and key developmental transitions, and strongly implicate the Skp1 modification pathway in decoding the $\mathrm{O}_{2}$ signal.

\section{Significance of $\mathrm{O}_{2}$ for control of polarity and terminal differentiation}

Formation of the novel cyst-like structures is compared to normal development at an air-water interface as a backdrop to interpreting the role of Skp1 modification in $\mathrm{O}_{2}$ signaling. During normal development at an airwater interface, the tip emerges at the apex of the hemispherical aggregate and exerts a dominant role in

\section{A. Skp1 modification pathway}

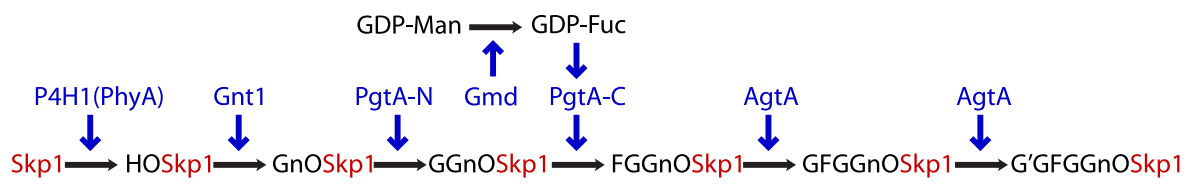

(Gal $\alpha 1$, ?Gal $\alpha 1,3$ Fuc $\alpha 1,2$ Gal $\beta 1,3 G \mid c N A c \alpha 1,4$ (trans)Pro143-Skp1)

B. Role of glycosylation: morphology

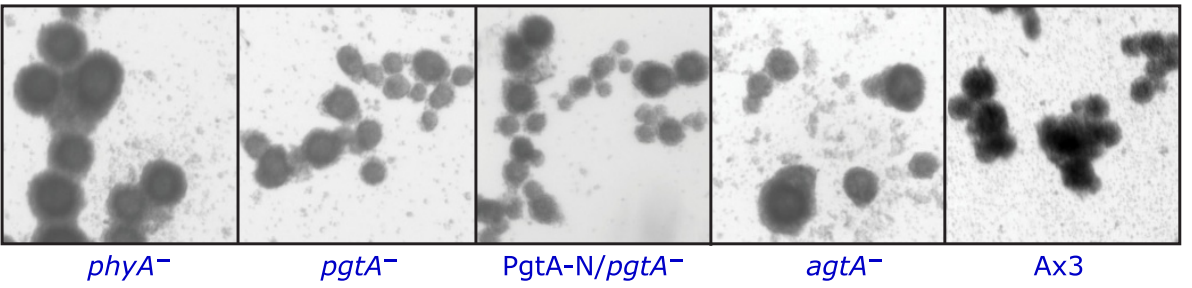

C. Role of glycosylation: spore numbers

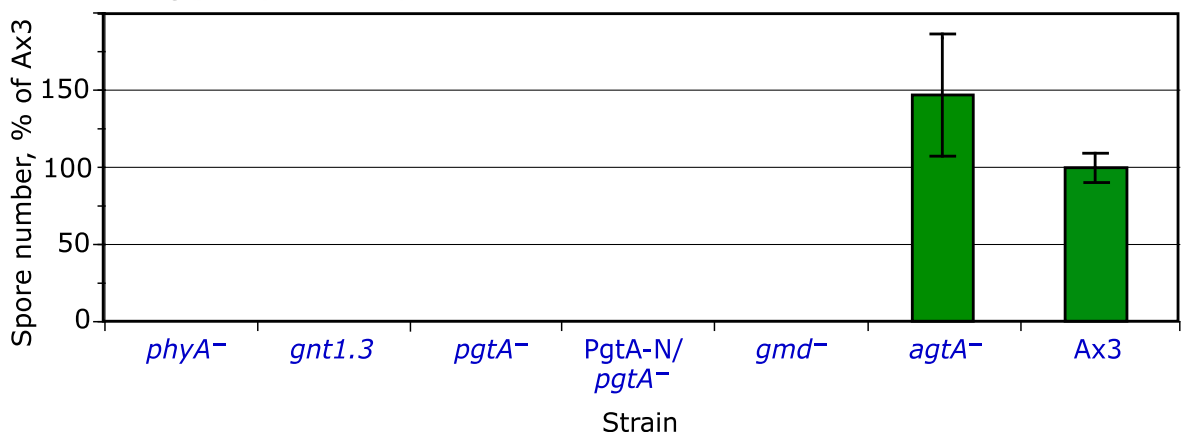

Figure 6 Dependence of spore differentiation on Skp1 glycosylation. (A) Schematic of the Skp1 modification pathway. Enzymes are in indicated by gene names; $\mathrm{G}=\mathrm{Gal} ; \mathrm{F}=\mathrm{Fuc} ; \mathrm{Gn}=\mathrm{GlcNAc}$. (B) Normal cells (Ax3) and modification pathway mutants were developed at $100 \% \mathrm{O}_{2}$ in submerged conditions for $72 \mathrm{~h}$. All strains formed similar tight aggregates, except that Ax3 aggregates exhibited dense cores; agt $\mathrm{A}^{-}$aggregates formed few spores in this trial. (C) Spore numbers were determined as in Figure 4. Average values \pm SEM from 5 independent trials are shown. The wide error bar for agt $A^{-}$cells results from a range of outcomes from near zero to more than Ax3. 


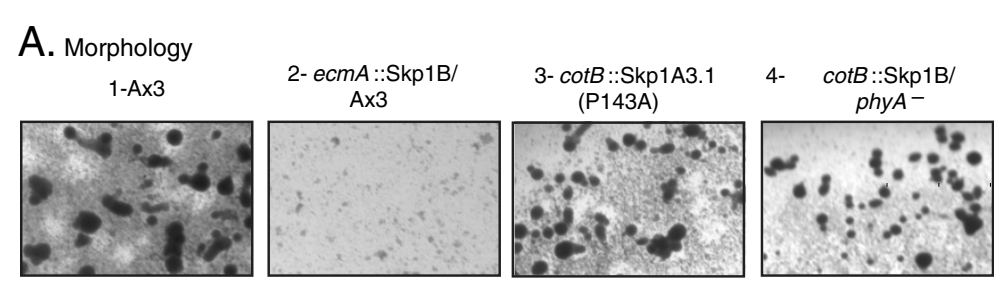

B. Spore differentiation

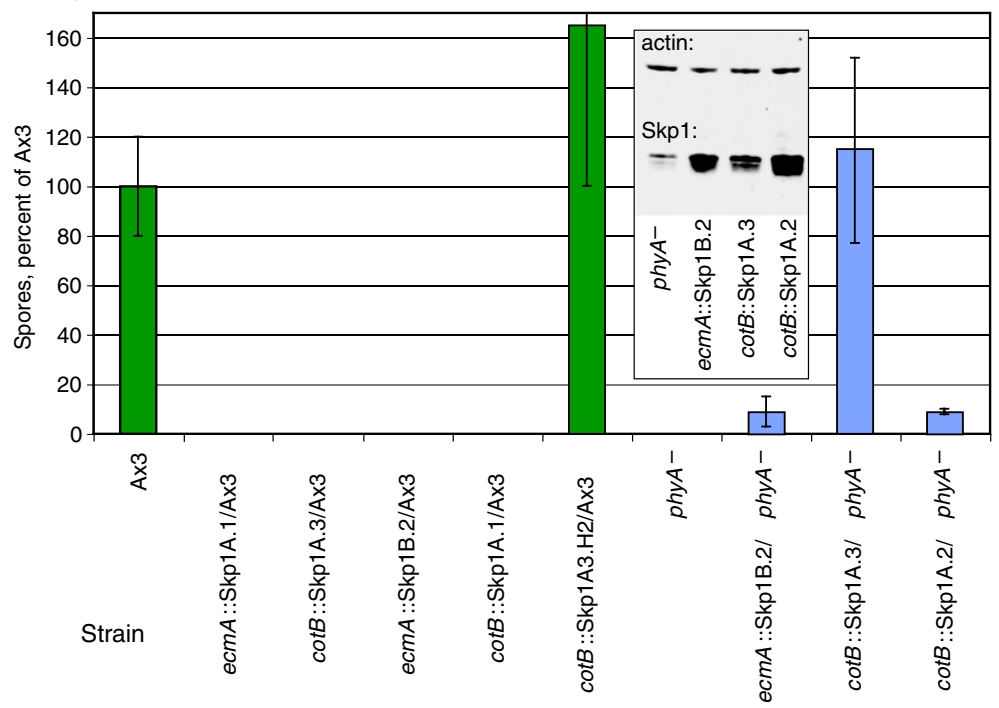

Figure 7 Dependence on Skp1 expression level. Strains overexpressing Skp1A or Skp1B under control of either the ecmA or $\cot B$ promoter, in either a normal or phy $A^{-}$background, were developed in submerged conditions beneath $100 \% \mathrm{O}_{2}$ for $72 \mathrm{~h}$. Typical results from selected strains are shown. (A) All tested strains formed tight aggregates except those overexpressing wild-type Skp1 in a phy $A^{+}$background, which remained as small, loose aggregates. (B) Spore numbers were counted and normalized to Ax3 spore counts in the same trial. Average values \pm SEM from 2-3 independent trials are reported. Inset shows a Western blot for Skp1, showing its level of overexpression in the phy $A^{-}$strains.

controlling elongation into a slug, slug migration, internal cell dynamics, and the induction and orchestration of the morphogenetic movements of culmination $[13,14,16,20,37]$. The tip, composed of prestalk-type cells [38], senses environmental signals, including $\mathrm{O}_{2}$ potentially, and relays the information to the other slug cells to follow suit (Figure 8, upper track). In previous submerged development studies, cells were shaken under an atmosphere of high $\mathrm{O}_{2}$ and the aggregates elongated into slug-like structures in which prestalk and prespore cells segregated toward opposite ends and terminally differentiated in situ [22,30,31,39]. In the absence of stirring as described here, cell aggregates instead become spherical cysts in which internal prespore and spore cells are surrounded by stalk cells. These findings suggest that $\mathrm{O}_{2}$ contributes to patterning and terminal differentiation, as follows (Figure 8, lower track). Given that $\mathrm{O}_{2}$ is metabolically depleted in the aggregate center, a gradient of $\mathrm{O}_{2}$ occurs with the highest levels at the aggregate surface [39] where the $\mathrm{O}_{2}$ level is expected to be uniform all they way around. Based on studies in capillaries [40] and in agar immobilized aggregates [39], it is likely that the higher $\mathrm{O}_{2}$ level at the aggregate surface attracts spontaneously differentiated prestalk cells and triggers their terminal differentiation. This is consistent with the transient existence of a monolayer of prestalk-like cells that has been observed at the slug surface [41]. Higher than ambient $\mathrm{O}_{2}$ might be required as a consequence of the submerged condition in which replacement diffusion of $\mathrm{O}_{2}$ lags behind metabolic consumption. In the absence of orienting signals in this isotropic setting, the aggregate remains radially-polarized. However, at the airwater interface, tip formation initiates at the apex of the aggregate owing to highest $\mathrm{O}_{2}$ accessibility, which becomes stabilized as its smaller radius of surface curvature ensures greatest gas exchange with the underlying cells. The interior prespore cells, experiencing relative hypoxia owing to metabolic consumption of $\mathrm{O}_{2}$, might not normally differentiate until culmination permits aerial exposure to atmospheric $\mathrm{O}_{2}$ levels or modulates metabolites that regulate PhyA and the glycosyltransferases. The idea that hypoxic niches regulate cell differentiation has precedent in studies on animal stem cells and maize germ cells $[42,43]$. 
$\mathrm{NH}_{3}$, a volatile metabolite released during the massive breakdown of protein during development [44], has also been implicated as a polarity factor and inhibits the slug-tofruit switch [16]. Since $\mathrm{NH}_{3}$ is expected to diffuse away most at the same surfaces that $\mathrm{O}_{2}$ is expected to diffuse in, the two compounds may play complementary inhibitory and activating roles that tune developmental decisions. Thus, while hypoxic or $p h y A^{-}$preculminants may still form tips at the air-water interface [24] due to the $\mathrm{NH}_{3}$ effect, the spherical shapes assumed by phy $A^{-}$slugs after long periods of migration [5] might reflect eventual depletion of the $\mathrm{NH}_{3}$ signal as protein is finally consumed. The isotropic environment during static submerged development may thwart formation of orienting $\mathrm{NH}_{3}$ as well thereby resulting in radial polarization, and high $\mathrm{NH}_{3}$ in the interior is expected to promote sporulation [45]. Since $\mathrm{NH}_{3}$-signaling is mediated in part by $\mathrm{NH}_{3}$-transporter/sensors [16,17], investigation of genetic interactions with phyA may allow understanding of the interplay with Skp1 modification.

\section{Role of Skp1 prolyl hydroxylation in tight aggregate formation}

Tight aggregate formation depended on an elevated $\mathrm{O}_{2}$ level of $\geq 40 \%$, but this was inhibited when Skp1 (either isoform) was overexpressed under either developmental promoter (Figure 7A). This correlates with the 7-hr delay of the loose-to-tight aggregate transition of these overexpression strains at the air-water interface [10]. Interestingly, inhibition of tight aggregate formation was partially relieved when Skp1 was overexpressed in a phyA-mutant background, which also relieved the delay on filters. Consistent with a requirement for modification, overexpression of Skp1A3(P143A), which cannot be hydroxylated, is not inhibitory (Figure 7A, B). The opposing effects of Skp1 overexpression and inhibiting its modification are consistent with a model in which modification activates Skp1 and its role in polyubiquitination and breakdown of a hypothetical activator of cyst formation.

\section{Role of Skp1 prolyl hydroxylation and glycosylation in sporulation}

A second function of the pathway was revealed by the essentially complete failure of the interior prespore cells to differentiate in the $p h y A^{-}$strain, whereas stalk cell differentiation was qualitatively unaffected (Figures 3, 4). The blockade was overcome when PhyA was overexpressed in prestalk and to a lesser extent prespore cells

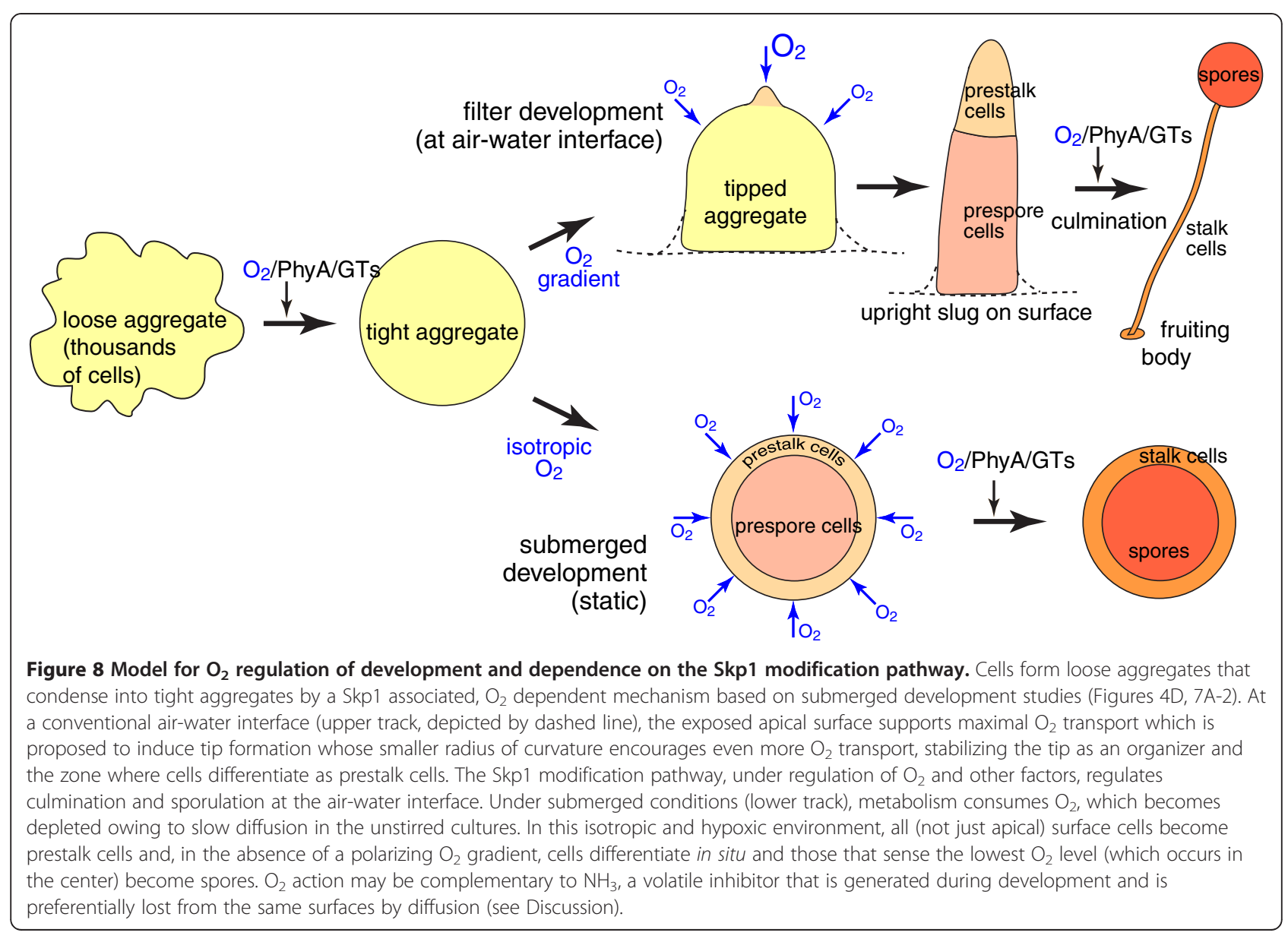


(Figure $4 \mathrm{~B}$ ), so control by $\mathrm{O}_{2}$ may be mediated via prestalk cells. This is consistent with evidence that prestalk cells can regulate sporulation via processing of spore differentiation factor- 1 and $-2[33,34]$. However, the role of PhyA appears complex because overexpression in prestalk cells in the $p h y A^{+}$(wild-type) background inhibited sporulation, as if relative levels of $\mathrm{O}_{2}$ signaling between cell types could be important. The blockade was also partially overcome when PKA activity was promoted by overexpression of its catalytic domain under its own promoter (Figure 4B). Since PKA expression in prespore cells was previously shown to be sufficient for activating sporulation [46], PhyA may signal upstream of PKA as suggested for its role in culmination on filters [24].

Hydroxylated Skp1 is a substrate for Gnt that in turn generates a substrate for PgtA, and then AgtA, resulting in formation of the pentasaccharide on Hyp143 (Figure 6A). Mutants lacking enzymes to extend to the trisaccharide state were also unable to sporulate at high $\mathrm{O}_{2}$ (Figures 6B,C), suggesting that hydroxylation supports extension of the glycan chain to three or more sugars to trigger sporulation. Though the preceding culmination step (on filters) exhibited more modest dependence on addition of the first two sugars (at lower $\mathrm{O}_{2}$ levels) [5], the more dramatic difference in the static submerged model may simply result from failure to achieve a critical threshold of $\mathrm{O}_{2}$ in the cyst interior. The greater difference was in the role of AgtA, whose contribution was almost as important for culmination as PhyA [9] but was unnecessary for submerged sporulation. Thus the role of AgtA appears to be specialized for culmination compared to sporulation.

The requirement of PhyA for sporulation was partially overcome by overexpression of Skp1 (Figure 7). This suggests that PhyA action normally promotes Skp1 activity, and its absence can be bypassed by excess Skp1. A related effect was observed on filter development, where Skp1 overexpression inhibited sporulation at high $\mathrm{O}_{2}$ levels that allowed culmination, but removal of PhyA blocked inhibition [10], indicating that PhyA tunes Skp1 activity. This is consistent with activation of Skp1 polyubiquitination activity toward an inhibitor. In comparison, the effect of Skp1 modification on culmination implied inhibition of Skp1 breakdown activity toward a hypothetical activator [10,11], and the effects on cyst formation (assessed morphologically) above suggested activation of breakdown activity toward an activator. These disparate effects are consistent with what is known about the SCF family of E3 ubiquitin-ligases, which polyubiquitinate different substrates depending on which Fbox protein is present. Furthermore, these Ub-ligases can have opposite effects via auto-polyubiquitination of the F-box protein itself, which results in protection of the substrate receptor [6,7]. Conceivably, Skp1 modification may selectively affect these different activities.

\section{$\mathrm{O}_{2}$ is limiting for Skp1 hydroxylation in submerged culture and mechanistic implications}

In submerged development, substantial levels of unmodified Skp1 (Figure 5D) accumulated at 5\% and 21\% $\mathrm{O}_{2}$. Since i) there is no evidence for enzymatic reversal of hydroxylation or glycosylation, ii) the level of Skp1 was similar at different $\mathrm{O}_{2}$ levels, and iii) Skp1 turns over with a half-life of $12-18 \mathrm{~h}$ [5], it is likely that appearance of unmodified Skp1 was due to failure to hydroxylate nascent Skp1. Since the total Skp1 pool becomes $95 \%$ hydroxylated at $\geq 40 \% \mathrm{O}_{2}$ (Figure $5 \mathrm{D}$ ), $\mathrm{O}_{2}$ is likely rate-limiting for Skp1 prolyl hydroxylation. This is consistent with co-expression evidence that PhyA is rate limiting for Skp1 hydroxylation [10]. Since sporulation is minimal at $40 \% \mathrm{O}_{2}$ even though the steady-state pool of Skp1 appears fully modified, it may be that $\mathrm{O}_{2}$ and PhyA have additional or alternative mechanisms for controlling sporulation. However, it should also be considered that a several hour delay in the hydroxylation of nascent Skp1, which might be most important for partnering with nascent F-box proteins, would have escaped detection against the background of total Skp1 using our methods.

Since the Skp1/F-box protein complex is characterized by a high affinity [29] that is increased by hydroxylation as suggested in Figure 1B (M.O. Sheikh and C.M. West, unpublished data), we propose that even transient accumulation of unmodified Skp1 will influence the spectrum of complexes with one or more of the $\sim 38$ predicted F-box proteins that are strongly up and/or down-regulated at various times during development based on RNAseq data [47] (unpublished studies). This in turn may affect the timing of developmental transitions via effects on the stability of F-box proteins and hypothetical F-box protein substrates (activators and inhibitors) that normally control aggregation, slug formation, culmination and sporulation [e.g., 48]. Figure 2B shows that $\mathrm{O}_{2}$ exposure of $1-3 \mathrm{~h}$ can rescue culmination of hypoxic slugs, consistent with a transient role that might correlate with expression of a specific F-box protein. Current studies are focused on how Skp1 modification influences $\mathrm{E}^{\mathrm{SCF}}$ ubiquitin-ligase assembly and activity.

These findings in social amoebae may be pertinent to numerous protist groups, including other amoebae (e.g., Acanthamoeba), plant pathogens (Phytophthora), diatoms (brown algae), green algae (Chlamydomonas), ciliates (Tetrahymena), and apicomplexans including Toxoplasma, whose $\mathrm{O}_{2}$ dependence have been little studied but whose genomes harbor Skp1 modification pathway-like genes [11]. For example, recent studies [4] 
showed that the related Skp1 modification pathway supports growth of Toxoplasma in cultured fibroblasts especially at low $\mathrm{O}_{2}$.

\section{Conclusions}

In an isotropic submerged environment under high $\mathrm{O}_{2}$, starved Dictyostelium cells form cyst-like structures in which terminal differentiation occurs in a radially symmetrical pattern consisting of external stalk cells and internal spores. Low $\mathrm{O}_{2}$ is rate-limiting for the hydroxylation and subsequent glycosylation of Skp1, which correlates qualitatively with inhibition of spore differentiation. Genetic perturbations indicate the importance of Skp1 hydroxylation and glycosylation for activating Skp1 activity in regulating cyst formation and sporulation, in addition to previous evidence for its inhibition in regulating culmination at an air-water interface. The findings support a model in which environmental control of Skp1 modification differentially influences sequential developmental transitions via polyubiquitination and degradation of F-box proteins and their respective regulatory factor substrates.

\section{Abbreviations}

Hyp: (4R,2S)-hydroxyproline (aka 4(trans)-hydroxy-L-proline); mAb: Monoclonal antibody; pAb: Polyclonal antibody; PhyA: Prolyl 4-hydroxylase-1 from $D$. discoideum; PKA: Protein kinase A; SCF: E3 ubiquitin ligase sub-complex consisting of Skp1, a cullin-1, an F-box protein, and Rbx1; SEM: Standard error of the mean; Ub: Ubiquitin.

\section{Competing interests}

The authors declare that they have no competing interests.

\section{Authors' contributions}

RSG performed initial experimentation including optimizations. ZAW broadened the scope of the study to include the complete mutant panel, and wrote the first draft. YX confirmed all the findings and conducted most of the molecular characterizations. CMW trained the students, coordinated the study, conducted some experiments, and wrote the manuscript which was approved by all authors.

\section{Acknowledgments}

We are grateful to Jim Henthorn at the Flow \& Image Cytometry Lab at OUHSC for assistance in the confocal imaging. Haitham Abd El-Moaty provided valuable assistance early in the project. Funding was provided by $\mathrm{NIH}$ grants RO1 GM037539 and R01 GM084383, grant HR10-181 from the Oklahoma Center for the Advancement of Science and Technology (OCAST), and a grant to the Summer Undergraduate Research Program (SURE) program from the OUHSC Graduate School and the Provost's Office.

\footnotetext{
Author details

'Department of Biochemistry and Molecular Biology, Oklahoma Center for Medical Glycobiology, University of Oklahoma Health Sciences Center, 975 NE 10th St., BRC 413, OUHSC, Oklahoma City, OK 73104, USA. ${ }^{2}$ current address: Department of Molecular Microbiology, Washington University Medical School Campus, Box 8230660 South Euclid Avenue, St. Louis, MO 63110, USA.
}

Received: 28 June 2012 Accepted: 11 October 2012

Published: 25 October 2012

\section{References}

1. Gorres KL, Raines RT: Prolyl 4-hydroxylase. Crit Rev Biochem Mol Biol 2010, 45:106-124.
2. Kaelin WG Jr, Ratcliffe PJ: Oxygen sensing by metazoans: the central role of the HIF hydroxylase pathway. Mol Cell 2008, 30:393-402.

3. van der Wel H, Ercan A, West CM: The Skp1 prolyl hydroxylase of Dictyostelium is related to the HIFa-class of animal prolyl 4-hydroxylases. J Biol Chem 2005, 280:14645-14655

4. Xu Y, Brown KA, Wang ZA, van der Wel H, Teygong C, Zhang D, Blader IJ, West CM: The Toxoplasma Skp1 protein is modified by a cytoplasmic prolyl 4-hydroxylase associated with oxygen sensing in the social amoeba Dictyostelium. J Biol Chem 2012, in press.

5. Zhang D, van der Wel H, Johnson JM, West CM: The Skp1 prolyl 4hydroxylase of Dictyostelium mediates glycosylation-independent and -dependent responses to $\mathrm{O}_{2}$ without affecting Skp1 stability. J Biol Chem 2012, 287:2006-2016.

6. Willems AR, Schwab M, Tyers MA: Hitchhiker's guide to the cullin ubiquitin ligases: SCF and its kin. Biochim Biophys Acta 2004, 1695:133-170.

7. Deshaies RJ, Joazeiro CA: RING domain E3 ubiquitin ligases. Annu Rev Biochem 2009, 78:399-434.

8. van der Wel H, Fisher SZ, West CM: A bifunctional diglycosyltransferase forms the Fuca1,2Galß1,3-disaccharide on Skp1 in the cytoplasm of Dictyostelium. J Biol Chem 2002, 277:46527-46534.

9. Wang ZA, van der Wel H, Vohra Y, Buskas T, Boons G-J, West CM: Role of a cytoplasmic dual-function glycosyltransferase in $\mathrm{O}_{2}$-regulation of development in Dictyostelium. J Biol Chem 2009, 284:28896-28904.

10. Wang ZA, Singh D, van der Wel H, West CM: Prolyl hydroxylation- and glycosylation-dependent functions of Skp1 in $\mathrm{O}_{2}$-regulated development of Dictyostelium. Dev Biol 2011, 349:283-295.

11. West CM, Wang ZA, van der Wel H: A cytoplasmic prolyl hydroxylation and glycosylation pathway modifies Skp1 and regulates $\mathrm{O}_{2}$-dependent development in Dictyostelium. Biochim Biophys Acta 2010, 1800:160-171.

12. Kessin RH: Dictyostelium - Evolution, Cell Biology, and the Development of Multicellularity. New York: Cambridge University Press; 2001.

13. Schaap P: Evolutionary crossroads in developmental biology: Dictyostelium discoideum. Development 2011, 138:387-396.

14. Williams JG: Dictyostelium finds new roles to model. Genetics 2010, 185:717-726.

15. Bonner JT, Lamont DS: Behavior of cellular slime molds in the soil. Mycologia 2005, 97:178-184.

16. Kirsten $\mathrm{JH}$, Xiong $\mathrm{Y}$, Dunbar AJ, Rai $\mathrm{M}$, Singleton CK: Ammonium transporter $\mathrm{C}$ of Dictyostelium discoideum is required for correct prestalk gene expression and for regulating the choice between slug migration and culmination. Dev Biol 2005, 287:146-156.

17. Yoshino R, Morio T, Yamada Y, Kuwayama H, Sameshima M, Tanaka Y, Sesaki $H$, lijima M: Regulation of ammonia homeostasis by the ammonium transporter AmtA in Dictyostelium discoideum. Eukaryot Cell 2007, 6:2419-2428.

18. Schindler J, Sussman M: Ammonia determines the choice of morphogenesis pathways in Dictyostelium discoideum. J Mol Biol 1977, 116:161-169.

19. Singleton CK, Zinda MJ, Mykytka B, Yang P: The histidine kinase dhkC regulates the choice between migrating slugs and terminal differentiation in Dictyostelium discoideum. Dev Biol 1998, 203:345-357.

20. Siegert F, Weijer CJ: Three-dimensional scroll waves organize Dictyostelium slugs. Proc Natl Acad Sci USA 1992, 89:6433-6437.

21. Sandonà D, Gastaldello S, Rizzuto R, Bisson R: Expression of cytochrome c oxidase during growth and development of Dictyostelium. J Biol Chem 1995, 270:5587-5593.

22. Sternfeld J, Bonner JT: Cell differentiation in Dictyostelium under submerged conditions. Proc Natl Acad Sci USA 1977, 74:268-271.

23. West CM, Erdos GW: The expression of glycoproteins in the extracellular matrix of the cellular slime mold Dictyostelium discoideum. Cell Differ 1988, 23:1-16

24. West $\mathrm{CM}$, van der Wel $\mathrm{H}$, Wang ZA: Prolyl 4-hydroxylase-1 mediates $\mathrm{O}_{2}-$ signaling during development of Dictyostelium. Development 2007, 134:3349-3358.

25. Ercan A, Panico M, Sutton-Smith M, Dell A, Morris HR, Matta KL, Gay DF, West CM: Molecular characterization of a novel UDP-Gal:fucoside alpha3galactosyltransferase that modifies Skp1 in the cytoplasm of Dictyostelium. J Biol Chem 2006, 281:12713-12721.

26. Schiller B, Hykollari A, Voglmeir J, Pöltl G, Hummel K, Razzazi-Fazeli E, Geyer $\mathrm{R}$, Wilson IB: Development of Dictyostelium discoideum is associated with alteration of fucosylated N-glycan structures. Biochem J 2009, 423:41-52. 
27. Sussman M: Cultivation and synchronous morphogenesis of Dictyostelium under controlled experimental conditions. Meth Cell Biol 1987, 28:9-29.

28. Metcalf T, Kelley K, Erdos GW, Kaplan L, West CM: Formation of the outer layer of the Dictyostelium spore coat depends on the inner-layer protein SP85/PsB. Microbiology 2003, 149:305-317.

29. van der Wel H, Johnson JM, Xu Y, Karunaratne CV, Wilson KD, Vohra Y, Boons GJ, Taylor CM, Bendiak B, West CM: Requirements for Skp1 processing by cytosolic prolyl 4(trans)-hydroxylase and a-Nacetylglucosaminyltransferase enzymes involved in $\mathrm{O}_{2}$ signaling in Dictyostelium. Biochemistry 2011, 50:1700-1713.

30. Sternfeld J, David CN: Ammonia plus another factor are necessary for differentiation in submerged clumps of Dictyostelium. J Cell Sci 1979, 3:181-191.

31. West CM: Comparative analysis of spore coat formation, structure, and function in Dictyostelium. Int Rev Cytol 2003, 222:237-293.

32. Richardson DL, Loomis WF, Kimmel AR: Progression of an inductive signal activates sporulation in Dictyostelium discoideum. Development 1994, 120:2891-2900,

33. Anjard C, Su Y, Loomis WF: Steroids initiate a signaling cascade that triggers rapid sporulation in Dictyostelium. Development 2009, 136:803-812.

34. Anjard C, Su Y, Loomis WF: The polyketide MPBD initiates the SDF-1 signaling cascade that coordinates terminal differentiation in Dictyostelium. Eukaryot Cell 2011, 10:956-963.

35. Sassi S, Sweetinburgh M, Erogul J, Zhang P, Teng-Umnuay P, West CM: Analysis of Skp1 glycosylation and nuclear enrichment in Dictyostelium. Glycobiology 2001, 11:283-295.

36. O'Day DH, Keszei A: Signalling and sex in the social amoebozoans. Biol Rev Camb Philos Soc 2012, 87:313-329.

37. Dormann D, Weijer CJ: Propagating chemoattractant waves coordinate periodic cell movement in Dictyostelium slugs. Development 2001, 128:4535-4543.

38. Wang HY, Williams JG: Identification of a target for CudA, the transcription factor which directs formation of the Dictyostelium tip organiser. Int J Dev Biol 2010, 54:161-165.

39. Sternfeld J, David CN: Oxygen gradients cause pattern orientation in Dictyostelium cell clumps. J Cell Sci 1981, 50:9-17.

40. Bonner JT, Compton KB, Cox EC, Fey P, Gregg KY: Development in one dimension: the rapid differentiation of Dictyostelium discoideum in glass capillaries. Proc Natl Acad Sci USA 1995, 92:8249-8253.

41. Wilkins MR, Williams KL: The extracellular matrix of the Dictyostelium discoideum slug. Experientia 1995, 51:1189-1196.

42. Simon MC, Keith B: The role of oxygen availability in embryonic development and stem cell function. Nat Rev Mol Cell Biol 2008, 9:285-296.

43. Kelliher $\mathrm{T}$, Walbot $\mathrm{V}$ : Hypoxia triggers meiotic fate acquisition in maize. Science 2012, 237:345-348.

44. Hames BD, Ashworth JM: The metabolism of macromolecules during the differentiation of myxamoebae of the cellular slime mould Dictyostelium discoideum containing different amounts of glycogen. Biochem J 1974, 142:301-315.

45. Gross JD: Developmental decisions in Dictyostelium discoideum. Microbio Rev 1994, 58:330-351.

46. Mann SK, Richardson DL, Lee S, Kimmel AR, Firtel RA: Expression of CAMPdependent protein kinase in prespore cells is sufficient to induce spore cell differentiation in Dictyostelium. Proc Natl Acad Sci USA 1994, 91:10561-10565.

47. Parikh A, Miranda ER, Katoh-Kurasawa M, Fuller D, Rot G, Zagar L, Curk T, Sucgang R, Chen R, Zupan B, Loomis WF, Kuspa A, Shaulsky G: Conserved developmental transcriptomes in evolutionarily divergent species. Genome Biol 2010, 11:R35.

48. Mohanty S, Lee S, Yadava N, Dealy MJ, Johnson RS, Firtel RA: Regulated protein degradation controls PKA function and cell-type differentiation in Dictyostelium. Genes Dev 2001, 15:1435-1448.

doi:10.1186/1471-213X-12-31

Cite this article as: Xu et al:: Role of the Skp1 prolyl-hydroxylation/ glycosylation pathway in oxygen dependent submerged development of Dictyostelium. BMC Developmental Biology 2012 12:31.

\section{Submit your next manuscript to BioMed Central and take full advantage of:}

- Convenient online submission

- Thorough peer review

- No space constraints or color figure charges

- Immediate publication on acceptance

- Inclusion in PubMed, CAS, Scopus and Google Scholar

- Research which is freely available for redistribution 